\title{
Time Series Study of Problem Solving Ability of Tadulako University Students Using Metacognitive Skill Based Learning Model
}

\author{
https://doi.org/10.3991/ijet.v14i21.11684 \\ Ijirana, Lukman Nadjamuddin( $\left.{ }^{\bowtie}\right)$ \\ Tadulako University, City of Palu, Indonesia \\ lukman.nadjamuddin.untadegmail.com
}

\begin{abstract}
The data of students problem solving ability was acquired through given test both prior to and after the implementation of metacognitive skill-based learning model (MSBL model) for stoichiometry and chemical equilibrium materials. Problem solving skill was measured using four indicators, consist of; understanding problem, Devising, implementing the plan and evaluating result. The overall students problem solving ability are classically categorized as good in each time of measurement providing the number of students with high minimum category were fewer than $60 \%$. The results indicate the improvement of student's ability to understand, to plan, to implement, and to evaluate the problem solving result gradually from prior to stoichiometry study, after the stoichiometry study, prior to chemical equilibrium study and after the chemical equilibrium study. Therefore, the students of chemistry education require time to be able to solve problems well.
\end{abstract}

Keywords-MSBL model, problem solving ability, time series, stoichiometry, and chemical equilibrium

\section{$1 \quad$ Introduction}

The purpose to learn chemistry is to have the ability to comprehend and to apply the concept, principle, law, chemical theories in order to solve problems in daily life. The students solving problems will have ability to think critically [1]. Problem solving is a behaviour directed to the purpose requiring an exact mental representative from problems and certain implementation method or strategic to attain the expected goals [2]. A person is regarded to have problem solving ability providing the person could implement the sequence of steps able to change the problems circumstance into goal and the sequence is the solution of the problems [3]. Thus, in solving problems, a person requires several sequences consist of to understand problems, to clarify goals, to devise plans, to implement the plans and to evaluate/crosscheck result [4]. Due to it, the basical things in attaining improvement of problem solving ability could be realized by using the metacognitive skill [5]. 
Metacognitive skill is an activity reflecting what would be done by someone when not knowing what to do (finding problems). Metacognitive skill influences a thinking process of students on how to implement what has been learned in solving problems [6]. The metacognition refers to the someone's thinking process to monitor and to controll the cognitive process in completing the assigments involving ability to arrange, to observe and to assess the idea towards what is happened or a skill of devising, monitoring and evaluating [7]. Metacognitive skill could develop by means of exercises and training in a learning [8].

Several researches directing to the metacognitive skill learning has been designed for ability of problem solving. A problem manipulating method based recitation learning model in order to improve the skill of metacognitive and chemistry problem solving [9].A metacognitive skill based learning model (MSBL model) [10] and developed the instruments of learning from the MBSL model to be implemented for the chemistry education students[11]. The result has indicated that the MSBL model could improve the conceptual understanding and students ability of understanding problems, devising, implementing the average problem deciphering at high categort and evaluating the high enough category.

Therefore, MSBL model has a probability to be implemented in the learning of chemistry for chemistry education students under focusing point on the study of problem solving ability improvement by time series.

\section{Method}

MSBL model is implemented to the chemistry education students at Tadulako University undertaking basic chemistry study. Total of samples are 67 students divided into two learning classes (first learning class and second learning class). The implementation of the model is conducted by the sequences of MSBL model involving by assessing the student's problem solving ability and by figuring the progress by time to time. Accordingly, the MSBL model is undergone through experiment quasi in a design within education setting [12].

Design of experimental quasi is applied in a modified form of Equivalent Time Series Design corresponding to the education setting[13]. The assessment utilizes repeated measurement or observation along certain period both prior to and after the learning using MSBL model. The modified Equivalent Time Series only using one group, consequently the implementation of the research is figured out as follows:

\begin{tabular}{|l|l|l|l|l|l|}
\hline $\mathbf{O}_{1}$ & $\mathbf{X}$ & $\mathbf{O}_{2}$ & $\mathbf{O}_{3}$ & $\mathbf{X}$ & $\mathbf{O}_{4}$ \\
\hline
\end{tabular}

Each of $\mathrm{O}_{1}$ and $\mathrm{O}_{2}$ is a test of chemical problem solving for both prior to and after the stoichiometry study. Furthermore, each of $\mathrm{O}_{3}$ and $\mathrm{O}_{4}$ is a test of chemical problem solving for both prior to and after the chemical equilibrium study. $\mathrm{X}$ is the process of learning using MSBL model in Stoichiometry and Chemical equilibrium topics. The evaluation of problem solving ability is analyzed descriptively quantitative [14]. 


\section{$3 \quad$ Result and Discussion}

The analysis of problem solving ability of the chemistry education students is intended to figure out the progress of students ability to solve problems by time series during the learning in two classes using MSBL model. The explanation about the students ability improvement in solving problems is reviewed from the achievement of criteria in succeeding the implementation of MSBL model during learning. The achievement of problem solving skill through MSBL model could be categorized as good when clasically the percentage of students having high and very high/perfect categories is fewer than $60 \%$. The data of students problem solving ability at first and second class are shown in Table 1 and Table 2 below.

Table 1. The percentage of Chemistry Education Students in Various Categories of Problem Solving Skill Prior to and After Studies of Stoichiometry and Chemical Equilibrium at First Class

\begin{tabular}{|c|c|c|c|c|c|c|c|c|c|c|c|c|c|c|c|c|}
\hline \multirow{3}{*}{ Category } & \multicolumn{8}{|c|}{ Stoichiometry } & \multicolumn{8}{|c|}{ Chemical Equilibrium } \\
\hline & \multicolumn{2}{|c|}{$\begin{array}{c}\text { Problem } \\
\text { under- } \\
\text { standing } \\
(\%)\end{array}$} & \multicolumn{2}{|c|}{$\begin{array}{c}\text { Devising } \\
\text { (\%) }\end{array}$} & \multicolumn{2}{|c|}{$\begin{array}{c}\text { Imple- } \\
\text { menting } \\
(\%)\end{array}$} & \multicolumn{2}{|c|}{$\begin{array}{c}\text { Evaluating } \\
\text { (\%) }\end{array}$} & \multicolumn{2}{|c|}{$\begin{array}{l}\text { Problem } \\
\text { under- } \\
\text { standing } \\
(\%)\end{array}$} & \multicolumn{2}{|c|}{$\begin{array}{c}\text { Devising } \\
\text { (\%) }\end{array}$} & \multicolumn{2}{|c|}{$\begin{array}{c}\text { Imple- } \\
\text { menting } \\
(\%)\end{array}$} & \multicolumn{2}{|c|}{$\begin{array}{l}\text { Evaluat- } \\
\text { ing (\%) }\end{array}$} \\
\hline & T0 & $\mathrm{T} 1$ & T0 & $\mathrm{T} 1$ & T0 & $\mathrm{T} 1$ & T0 & $\mathrm{T} 1$ & T0 & $\mathrm{T} 1$ & T0 & $\mathrm{T} 1$ & T0 & $\mathrm{T} 1$ & T0 & $\mathrm{T} 1$ \\
\hline Very High & 0 & 85 & 0 & 52 & 0 & 55 & 0 & 21 & 55 & 100 & 0 & 67 & 0 & 45 & 0 & 6 \\
\hline High & 0 & 15 & 0 & 27 & 0 & 36 & 0 & 3 & 15 & 0 & 3 & 27 & 0 & 24 & 0 & 46 \\
\hline Medium & 0 & 0 & 0 & 21 & 0 & 1 & 0 & 27 & 9 & 0 & 6 & 3 & 6 & 21 & 6 & 18 \\
\hline Low & 6 & 0 & 0 & 0 & 0 & 3 & 0 & 30 & 18 & 0 & 45 & 3 & 15 & 3 & 15 & 15 \\
\hline Very Low & 94 & 0 & 100 & 0 & 100 & 0 & 100 & 18 & 3 & 0 & 45 & 0 & 79 & 6 & 79 & 15 \\
\hline
\end{tabular}

$\mathrm{T} 0=$ Before; $\mathrm{T} 1=$ After

Table 2. The percentage of Chemistry Education Students in Various Categories of Problem Solving Skill Prior to and After Studies of Stoichiometry and Chemical Equilibrium at Second Class

\begin{tabular}{|c|c|c|c|c|c|c|c|c|c|c|c|c|c|c|c|c|}
\hline \multirow{3}{*}{ Category } & \multicolumn{8}{|c|}{ Stoichiometry } & \multicolumn{8}{|c|}{ Chemical Equilibrium } \\
\hline & \multicolumn{2}{|c|}{$\begin{array}{c}\text { Problem } \\
\text { under- } \\
\text { standing } \\
\text { (\%) }\end{array}$} & \multicolumn{2}{|c|}{$\begin{array}{l}\text { Devising } \\
\text { (\%) }\end{array}$} & \multicolumn{2}{|c|}{$\begin{array}{c}\text { Imple- } \\
\text { menting } \\
(\%)\end{array}$} & \multicolumn{2}{|c|}{$\begin{array}{c}\text { Evaluat- } \\
\text { ing (\%) }\end{array}$} & \multicolumn{2}{|c|}{$\begin{array}{l}\text { Problem } \\
\text { under- } \\
\text { standing } \\
(\%)\end{array}$} & \multicolumn{2}{|c|}{$\begin{array}{c}\text { Devising } \\
\text { (\%) }\end{array}$} & \multicolumn{2}{|c|}{$\begin{array}{l}\text { Imple- } \\
\text { menting } \\
(\%)\end{array}$} & \multicolumn{2}{|c|}{$\begin{array}{c}\text { Evaluat- } \\
\text { ing (\%) }\end{array}$} \\
\hline & T0 & $\mathrm{T} 1$ & T0 & $\mathrm{T} 1$ & T0 & $\mathrm{T} 1$ & T0 & $\mathrm{T} 1$ & T0 & $\mathrm{T} 1$ & T0 & $\mathrm{T} 1$ & T0 & $\mathrm{T} 1$ & T0 & $\mathrm{T} 1$ \\
\hline Very High & 0 & 91 & 0 & 12 & 0 & 6 & 0 & 3 & 47 & 100 & 0 & 76 & 0 & 47 & 0 & 6 \\
\hline High & 0 & 9 & 0 & 35 & 0 & 50 & 0 & 21 & 26 & 0 & 6 & 21 & 3 & 26 & 0 & 38 \\
\hline Medium & 0 & 0 & 0 & 53 & 0 & 44 & 0 & 18 & 15 & 0 & 12 & 0 & 0 & 15 & 0 & 21 \\
\hline Low & 35 & 0 & 0 & 0 & 0 & 0 & 0 & 18 & 6 & 0 & 15 & 3 & 21 & 9 & 18 & 32 \\
\hline Very Low & 65 & 0 & 100 & 0 & 100 & 0 & 100 & 41 & 6 & 0 & 68 & 0 & 76 & 3 & 82 & 3 \\
\hline
\end{tabular}

Data on table 3 and 4 apparently show the total of students with ability to develop strategies of chemical equilibrium's problem solving after the lesson for both classes have had good ability 
Paper-Time Series Study of Problem Solving Ability of Chemistry Education Students Using ...

Table 3. The Percentage of Chemistry Education Students with High and Very High Problem Solving Abilities Prior to and After The Studies of Stoichiometry and Chemical Equilibrium at First Class

\begin{tabular}{|l|c|c|c|c|}
\hline \multirow{2}{*}{ Ability } & \multicolumn{2}{|c|}{ Stoichiometry } & \multicolumn{2}{c|}{ Chemical Equilibrium } \\
\cline { 2 - 5 } & Before (\%) & After (\%) & Before (\%) & After (\%) \\
\hline Problem Understanding & 0 & 100 & 70 & 100 \\
\hline Devising & 0 & 79 & 3 & 84 \\
\hline Implementing & 0 & 91 & 0 & 69 \\
\hline Evaluating & 0 & 24 & 0 & 51 \\
\hline
\end{tabular}

Table 4. The Percentage of Chemistry Education Students with High and Very High Problem Solving Abilities Prior to and After The Studies of Stoichiometry and Chemical Equilibrium at Second Class

\begin{tabular}{|l|c|c|c|c|}
\hline \multirow{2}{*}{\multicolumn{1}{|c|}{ Ability }} & \multicolumn{2}{|c|}{ Stoichiometry } & \multicolumn{2}{c|}{ Chemical Equilibrium } \\
\cline { 2 - 5 } & Before (\%) & After (\%) & Before (\%) & After (\%) \\
\hline Problem Understanding & 0 & 100 & 73 & 100 \\
\hline Devising & 0 & 47 & 6 & 97 \\
\hline Implementing & 0 & 56 & 3 & 73 \\
\hline Evaluating & 0 & 24 & 0 & 44 \\
\hline
\end{tabular}

Table 4 show that a number of students who have ability to understand problems prior to the study of chemical equilibrium increases after the study, even reaching the maximum percentage $(100 \%)$. The fact proves that the training of metacognitive skill, discussion and self-evaluation in MSBL model could support the students to improve their abilities in identifying problems and determining the required goals although the material has not been taught. The main purpose of teacher in metacognition learning was how the students could have main role in the learning, improve awareness, and help to utilize the learning strategic for reaching the goals [15]. The implementation evidence supporting the success of students is derived from the activeness and positive response of the students during the lesson. Elaborating problem solving into collaborative learning, every student get involved with the partners to debate in collaboration process and to negotiate for enhancing knowledge[16].

Furthermore, the data in table show that percentage of students with ability to devise the problem solving of stoichiometry after MSBL model implementation at first class have attained the ability expected, yet different from second class with $47 \%$ only. By observing the assessment result data of students problem solving ability at second class (Table 2), the student's abilities to devise the problem solving generally remain in category of medium/satisfying (53\%). The achievement in that category is affected by students who have not been able to arrange strategies completely. A distinction emerges after chemical equilibrium study. The fact indicates that the success of metacognitive skill training is not only affected by teacher, but also by internal factors of the students. Student's abilities to be skilled on arranging strategies of problem solving at second class require time to reach the ability expected, since the achievement of the ability occurs gradually. 
Table 1 and 2 denote that prior to chemical equilibrium study, the total of students able to devise the problem solving well are 3-6\% only. It is higher than the pre-study of stoichiometry. It means that a number of students have been able to arrange strategy of problem solving by applying the concept of chemical equilibrium although it has not been taught yet. Someone who had skill to arrange strategies and to allocate time or attention prior to commence the problem solving would lead to decipher the problem well [17]. Thus, students who have been trained for metacognitive skill in stoichiometry study have had awareness to arrange strategies prior to do the problem solving in chemical equilibrium, as a result the ability progress would be better.

Some of researchers support that by the time the students able to devise a problem solving means they have comprehended, analyzed, interpreted, defined problems and connected cues of the problem statements to determine purposes [18]. The students doing this thinking process could be regarded have utilized their cognitive variable in the skill of interpreting as an important predictor from problem solving skill. The time the students process the problem, at the time they are doing the step of accepting cognitive [19]. It enables the students to locate the information in a cognitive structure net. the metacognitive skill of orientation and planning give the essential roles to prevent students from the trial-and-error approach and to enable the students in using the previous knowledge to determine what information has been given and what has been asked [20].

The result about the problem solving completion skill of the data above generally show that prior to the stoichiometry study, the chemistry education students of first implementation class have not been able to do the problem solving refer to the plan. Most of students ( $>50 \%$ ), teacher candidates, have an incomprehension to stoichiometry concepts well and low ability of math from their previous high school [21]. However, after the learning, the total of students having the ability achieves the good ability $(91 \%)$. It indicates the training of metacognitive skill implementation in the study of stoichiometry could improve the student's ability to solve problems according to the strategy. Accordingly, the success of the research is not separated from the implementation of the metacognitive skill strategy training of which the students could improve their abilities to solve stoichiometry problems well.

The success of chemical equilibrium problem solving is determined by the students ability to interpret the problem statements and to express the comprehension, factual knowledge, conceptual and procedural knowledge [22]. Therefore, the implementation of MSBL model guiding the students to solve problems systematically in the step of metacognitive skill implementation and the step of doing the follow-up plan leads the students to solve problems more improving. The process of problem solving and monitoring conducted by students during the implementation of the steps requires a thinking process to implement their knowledge, consequently it would affect the student to be more aware to their limited knowledge. The self-awareness of students leads to the emergence of self-motivation to learn more and to practice the problem solving. Monitoring skill involves the awareness of comprehension and performance of someone towards the assignment done [23].

Someone ability to solve problems depends on individual's knowledge and expertise [24]. It means not all the problems faced by someone are problem for another 
person because someone's difficulties to solve problems is not affected by intrinsic characteristic from the problems faced, yet depends on the problem solver's knowledge and experiences. Thus, seemingly the ability of students in the research is the consequence of the knowledge and many opportunities given to students to solve problems and to assess themselves towards their own knowledge and problem solving ability, hence they have a high self-confidence to be good problem solvers.

The total of students having the ability of result evaluating for both implementation classes show the lowest percentage among the other three problem solving ability's indicators. The percentage of students having this ability for both stoichiometry and chemical equilibrium studies at both classes have not reached the criteria determined in this research. The fact indicates the implementation of MSBL model has not been success to improve the student's ability to evaluate the result of the problem solving well. Nevertheless, a good phenomenon shown by students at both classes is the growth in number of students who could provide the logic evidences to correlate the obtained result by their comprehension of the mole concept, mass, molar, chemical formula, chemical equation, limiting reactant, chemistry basic laws implementation and equilibrium constant concept with the influential factors after the learning. There is an improvement of student's ability to evaluate a result by time to time although it is not the same as the other ability indicators.

The result of the research is apparently relevant to the Carroll argument [25] who has stated that several factors influencing towards the study result of the students consist of

- Time provided

- Individual ability

- Learning quality

- Environmental factor

In addition to the quality and environmental factors, other influencing factors indicated in this research are also the time provided and individual ability. According to the data, the training of evaluating skill requires not a short time, hence it should be continuously to have a good evaluating ability. The use of time period in this research (the MSBL model implementation's time period) apparently has not been optimal to maximize the success of the ability. Therefore, the skill is affected by time period of the training and the internal ability of the students.

\section{Conclusion}

The ability of students to understand, to devise and to implement the completion of stoichiometry and chemical equilibrium problems are in a highly probability of good achievement because no student has a low ability after the MSBL model implementation. The training of metacognitive skill within MSBL model consistently has guided the students to improve their ability to solve problems and to monitor the problem solving towards the desired purpose being better by time to time. The ability of chemistry education students to evaluate the result has not achieved the good criteria, yet it 
has shown the improvement to be good slowly by time to time although not the same as the improvement of understanding problems, devising and doing the problem solving

\section{Acknowledgement}

This study was supported by Tadulako University.

\section{References}

[1] R. Kirtikar, "A Problem-Solving Approach for Science Learning," 2 ed., International Conference New Persfectives In Science Education, 2010.

[2] P. Metallidou, "Pre-service and in-service teachers' metacognitive knowledge about problem-solving strategies," Teaching and Teacher Education, vol. 25, no. 1, hlm. 76-82, Jan 2009. https://doi.org/10.1016/j.tate.2008.07.002

[3] R. W. Weisberg, "Creativity. Understanding innovation in problem solving, science, invention, and the arts," dalam PRZEGLĄD PSYCHOLOGICZNY, vol. 50, Canada: John Wiley \& Sons, Inc, 2007, hlm. 251-253.

[4] J. Adair, Decision Making and Problem Solving Strategies. London, United Kingdom: Kogan Page Ltd, 2010.

[5] M. M. Cooper dan S. Sandi-Urena, "Design and Validation of an Instrument To Assess Metacognitive Skillfulness in Chemistry Problem Solving," J. Chem. Educ., vol. 86, no. 2, hlm. 240, Feb 2009. https://doi.org/10.1021/ed086p240

[6] P. Rompayom, C. Tambunchong, S. Wongyounoi, dan P. Dechsri, "The Development of Metacognitive Inventory to Measure Students' Metacognitive Knowledge Related to Chemical Bonding Conceptions." Paper presented at International Association for Educational Assessment (IAEA), 2010.

[7] M. P. Prytula, "Teacher Metacognition within the Professional Learning Community," IES, vol. 5, no. 4, hlm. p112, Jun 2012.

[8] V. R. Delclos dan C. Harrington, "Effects of Strategy Monitoring and Proactive Instruction on Children's Problem-Solving Performance," Journal of Educational Psychology, vol. 83, no. 1, hlm. 35-42, 1991. https://doi.org/10.1037//0022-0663.83.1.35

[9] C. J. Parker Siburt, A. N. Bissell, dan R. A. Macphail, "Developing Metacognitive and Problem-Solving Skills through Problem Manipulation,” J. Chem. Educ., vol. 88, no. 11, hlm. 1489-1495, Nov 2011.https://doi.org/10.1021/ed100891s

[10] Ijirana, "The design of instruction model based on the metacognitive skill for establishing problem solving ability and the understanding of chemical concept," dalam International conference on mathematics, sciences, technology, education and their applications, Makassar, Indonesia, 2014, hlm. 281-291.

[11] Ijirana, "Practicality assessment device development of learning model based metacognitive skill," dalam Internasional Seminar on Chemistry, 2015, hlm. 14-22.

[12] N. Nieveen dan E. Folmer, "Formative Evaluation in Educational Design Research," dalam Educational Design Research, Netherlands: Part A: An introduction, 2013, hlm. 152-169.

[13] J. M. Creswell, Educational Research: Planning, Conducting, and Evaluating Quantitative and Qualitative Research, 4 ed. Boston: Pearson Education, Inc, 2012. 
[14] W. Ketpichainarong, B. Panijpan, dan P. Ruenwongsa, "Enhanced learning of biotechnology students by an inquiry-based cellulase laboratory," International Journal of Environmental \& Science Education, vol. 5, no. 2, hlm. 169-187, 2010.

[15] F. Takallou, "The Effect of Metacognitive Strategy Instruction on EFL Learners' Reading Comprehension Performance and Metacognitive Awareness," The Asian EFL Journal, vol. 12, hlm. 272-300, 2011. https://doi.org/10.4304/jltr.5.5.1147-1152

[16] R. C. Dixon, K. C. Dixon, dan M. A. Mandi, "Online student centred discussion: Creating a collaborative learning environment," dalam Proceedings of ASCILITE - Australian Society for Computers in Learning in Tertiary Education Annual Conference, 2008, hlm. 256264.

[17] C. Balcikanli, "Metacognitive Awareness Inventory for Teachers (MAIT)," Electronic Journal of Research in Educational Psychology, vol. 9, no. 3, hlm. 1309-1332, 2011.

[18] K.-W. L. Lee, W.-U. Tang, N.-K. Goh, dan L.-S. Chia, "THE PREDICTING ROLE OF COGNITIVE VARIABLES IN PROBLEM SOLVING IN MOLE CONCEPT," Chem. Educ. Res. Pract., vol. 2, no. 3, hlm. 285-301, 2001. https://doi.org/10.1039/b1rp90029c

[19] A. L. Brown dan M. I. Walton, Problem Possing: Reflection and Aplication. New Jersey: Lwarences Elbow Association Ltd, 1995.

[20] A. Desoete dan M. Veenman, "Metacognition in Mathematics: Critical Issues on Nature, Theory, Assessment and Treatment," dalam Metacognition in Mathematics Education, New York: Nova Science Publishers, 2006, hlm. 1-10. https://doi.org/10.1007/s11858$\underline{010-0243-\mathrm{Z}}$

[21] R. Hanson, "Ghanaian Teacher Trainees' Conceptual Understanding of Stoichiometry," Journal of Education and e-Learning Research, vol. 3, no. 1, hlm. 1-8, 2016.

[22] A. Weerawardhana, B. Ferry, dan C. Brown, "Use Of Visualisation Software To Support Understanding Of Chemical Equilibrium: The Importance Of Appropriate Teaching Strategies," dalam Proceedings of the 23rd Annual Ascilite Conference: Who's learning? Whose technology?, Sidney, Australia: University of Wollongong Research Online, 2006.

[23] G. Schraw dan D. Moshman, "Metacognitive Theories," Educational Psichology Review, vol. 7, no. 4, hlm. 351-371, 1995. https://doi.org/10.1007/bf02212307

[24] T. Gok, "The General Assessment of Problem Solving Processes and Metacognition in Physics Education,” Eurasian Journal of Physics and Chemistry Education, vol. 2, no. 2, hlm. 110-122, 2010.

[25] B. R. Joyce, M. Weil, dan E. Calhoun, Models of Teaching, 8 ed. Yogyakarta: Pustaka Pelajar, 2011.

\section{Authors}

Ijirana is a Lecturer at Chemistry Education Study Pogram, Tadulako University, City of, Palu, Central Sulawesi-Indonesia. ijiranarizal@yahoo.co.id

Lukman Nadjamuddin is a Lecturer at History Education Study Program, Tadulako University, City of Palu, Central Sulawesi-Indonesia, lukman.nadjamuddin. untad@gmail.com.

Article submitted 2019-09-15. Resubmitted 2019-10-23. Final acceptance 2019-10-24. Final version published as submitted by the authors. 